\section{Cardioversion of atrial fibrillation}

Sir

In his overview of drug-related aspects of atrial fibrillation and electrical cardioversion, Dr Lip alluded to the respective roles of digoxin, amiodarone, and warfarin, ${ }^{1}$ a significant feature being the relationship between left ventricular dysfunction and the indications for pretreatment with these drugs. For example, notwithstanding the apparent inefficacy of digoxin for chemical cardioversion, ${ }^{2}$ the fact that left ventricular dysfunction is a risk factor for atrial fibrillation ${ }^{3,4}$ lends support to the hypothesis that the positive inotropic action of digoxin could enhance chemical cardioversion with this drug in clinical subgroups with co-existing left ventricular systolic failure. ${ }^{5} \mathrm{~A}$ provisional validation of this hypothesis comes from the documentation of a significant association between cardioversion success with low energy shocks, and pretreatment with drugs such as digoxin and amiodarone, ${ }^{6}$ which share the ability to improve left ventricular performance even in the presence of sinus rhythm. ${ }^{7,8}$ Atrial fibrillation is itself a risk factor for left ventricular systolic failure, ${ }^{9}$ and the latter is, in turn, a predisposition to left atrial thrombogenesis. ${ }^{10}$ The prevention of $d e$ novo thrombogenesis (whilst allowing preexisting thrombi to resolve) appears to be the basis for the success of warfarin-related prophylaxis against post-cardioversion embolism. ${ }^{\text {" }}$ So long as risk factors for thrombogenesis, such as left ventricular systolic failure and spontaneous echo contrast, persist, the risk of postcardioversion thromboembolism, will not be eliminated even if the left atrium and its appendage test negative for thrombosis by transoesophageal echocardiography, ${ }^{12,13}$ hence the justification for universal anticoagulation prior to electrical cardioversion. This caveat might be equally applicable to atrial flutter, following the documentation of a $21 \%$ prevalence of left atrial thrombi in 24 patients with atrial flutter, in some of whom left ventricular systolic failure again appeared to be a significant risk factor for left atrial thrombogenesis. $^{14}$

OMP JOLOBE

Department of Medicine for the Elderly, Tameside General Hospital, Ashton-Under-Lyne, Lancashire OL6 9RW, UK

1 Lip GYH. Cardioversion of atrial fibrillation. Postgrad Med F 1995; 71: 457-65.

2 Falk RH, Knowlton AA, Bernard SA, Gotlieb NE, Batnell NJ. Digoxin for converting recentonset atrial fibrillation to sinus rhythm. Ann Intern Med 1987; 106: 503-6.

3 Kinnel WB, Abbott RD, Savage DD, McNamara PM. Epidemiological features of chronic atrial fibrillation. (The Framingham Study). N Engl ₹ Med 1982; 306: 1018-22.

$4 \mathrm{Krahn} \mathrm{AD}$, Manfreda J, Tate RB, Mathewson FAL, Cuddy TE. The natural history of atrial fibrillation: incidence, risk factors, and progfibrillation: incidence, risk factors, and prog-
nosis in the Manitoba follow-up study. $A m \mathcal{J}$ nosis in the Manitoba

5 Falk RH, Leavitt JI. Digoxin for atrial fibrillation. A drug whose time has gone. Ann Intern

6 Dalzell G, Anderson J, Adgey AAJ. Factors determining success and energy requirements 1991; 78: 85-95.
7 Uretsky BF, Young JB, Shahidi E, Yellen LG, Harrison MC, Jolly K. Randomised study assessing the effect of digoxin withdrawal in patients with mild to moderate chronic congestive heart with mild to moderate chronic congestive heart
failure. Results of PROVED trial. $\Im \mathrm{Am}$ Coll Cardiol 1993; 22: 955-62.

8 Cardiol 1993; 22: 955-62. Hamer AWF, Askles LB, John JA. Beneficial
effects of low-dose amiodarone in patients with congestive cardiac failure: a placebo-controlled trial. F Am Coll Cardiol 1989; 14: 1768-74.

9 van Gelder IC, Crijns HJG, Blanksma PK, et al. Time course of hemodynamic changes and improvement of exercise tolerance after cardioversion of chronic atrial fibrillation unassociated with cardiac valve disease. Am I Cardiol 1993; 72: 560-6.

10 The Stroke Prevention in Atrial Fibrillation Investigators. Predictors of thromboembolism in atrial fibrillation II. Echocardiographic 116: $6-12$.

11 Collins LJ, Silverman DI, Douglas PS, Manning WJ. Cardioversion of non-rheumatic atrial ing WJ. Cardioversion of non-rheumatic atrial
fibrillation. Reduced thromboembolic complciations with 4 weeks of precardioversion anticoagulation are related to atrial thrombus resolution. Circulation 1995; 92: 156-9.

12 Black IW, Fatkin D, Sagar KB, et al. Exclusion of atrial thrombus by transoesophageal echocardiography does not preclude embolism after cardoversion of atrial fibrillation. Circulation 1994; 89: 2509-13.

13 Black IW, Hopkins AP, Lee LCL, Walsh WF. Evaluation of transoesophageal echocardiography before cardioversion of atrial fibrillation and futter in non-anticoagulated patients. $A m$ Heart $\mathcal{F}$ 1993; 126: 375-81.

14 Bikkina M,Alpert MA, Mulekar M, Shakoor A Bikkina M, Alpert MA, Mulekar M, Shakoor A,
Massey CV, Cavin A. Prevalence of intra-atrial thrombus in patients with atrial flutter. $A m \mathcal{F}$ Cardiol 1995; 76: 186-9.

This letter was shown to the author who responded as follows:

Sir,

I thank Dr OMP Jolobe for his interest in my review of cardioversion of atrial fibrillation. ${ }^{1}$

His letter raises several points that merit further discussion. Control of the ventricular response in chronic atrial fibrillation has traditionally been attempted with digoxin, although this drug is ineffective during exercise or when cathecholamine levels are high, or in attempting cardioversion to sinus rhythm. ${ }^{2,3}$ Digoxin may also make paroxysmal atrial fibrillation worse, resulting in an increased frequency of paroxysms, which occur at higher heart rates. ${ }^{4}$ These effects are related to the mechanisms of action of digoxin. Firstly, digoxin has some direct effect on atrioventricular nodal conduction, but the degree of control of the ventricular response due to this is modest and may require oral doses in excess of those generally used to control the resting heart rate, hence increasing the risk of toxicity. ${ }^{5}$ The predominant negative chronotropic effect of digoxin, however, is to increase vagal tone at rest which, in turn, decreases atrioventricular nodal conduction and probably increases the number of fibrillating wavelets in the atria. ${ }^{6,7}$ The increase in vagal tone also reduces the atrial refractory period, and thus paradoxically renders the atrium more susceptible to fibrillation. Therefore, digoxin alone is unlikely to be successful in the pharmacological cardioversion of atrial fibrillation or in maintenance of sinus rhythm.

Beneficial clinical effects of digoxin in heart failure have recently been demonstrated in digoxin withdrawal studies, although some authorities advise caution until results from prospective studies are available. ${ }^{8}$ In the study by Dalzell et al, ${ }^{9}$ an association between electrical (direct current) cardioversion success and prior treatment with digoxin was found only on univariate analysis, with the duration of atrial fibrillation being the only independent predictor of cardioversion success in multivariate analysis. Pretreatment with amiodarone, by contrast, is well-known to be effective in achieving cardioversion and sustaining sinus rhythm. ${ }^{10}$ Whether or not treatment of heart failure alone (with or without digoxin) allows cardioversion to sinus rhythm remains to be demonstrated. However, beneficial haemodynamic effects of treating heart failure, such as the reduction of intra-atrial pressures may be one mechanism. It should also be remembered that many patients with new-onset atrial fibrillation spontaneously revert to sinus rhythm, especially if an acute precipitating factor were present. ${ }^{1,3}$

Finally, Dr Jolobe comments on the relationship between left ventricular systolic failure and thrombogenesis. It has long been recognised that thromboembolism is a frequent cause of death in patients with congestive heart failure, whether or not in sinus rhythm, occurring in up to $30 \%$ of patients. ${ }^{11}$ In the pooled analysis of the atrial fibrillation trials, cardiac impairment was also a recognised contributory risk factor to stroke risk in atrial fibrillation. ${ }^{12}$

GREGORY YH LIP University Department of Medicine, City Hospital, Dudley Road, Birmingham B18 7QH, UK

1 Lip GYH. Cardioversion of atrial fibrillation. Postgrad Med f 1995; 71: 457-65.

2 Falk RH, Leavitt JI. Digoxin for atrial fibrillation: a drug whose time has gone? Ann Intern Med 1991; 114: 573-5.

3 Falk RH, Knowlton AA, Bernard SA, Gotlieb FE, Battinelli NJ. Digoxin for converting NE, Battinelli NJ. Digoxin for converting recent-onset atrial fibrillation to sinus rhythm. A randomized double-blinde

4 Lip GYH, Metcalf MJ, Rae AP. Management of paroxysmal atrial fibrilaltion. $Q \mathcal{F}$ Med 1993; 86: 467-72.

5 Redfors A. Digoxin dosage and ventricular rate at rest and exercise in patients with atrial fibrillation. Acta Med Scand 1971; 190: 321-33.

6 Bootsma BK, Hoelen AJ, Strackee J, Meijler FL. Analysis of the R-R intervals in patients with atrial fibrillation at rest and during exercise. Circulation 1970; 41: 783-94.

7 Knowlton AA, Falk RH. Paradoxical increase in heart rate before conversion to sinus rhythm in heart rate before conversion to sinus rhythm in patients with recent onset at

8 Poole Wilson P. Digoxin withdrawal in patients with heart failure (letter). $₹ \mathrm{Am}$ Coll Cardio 1994; 24: 578-9.

9 Dalzell GW, Anderson J, Adgey AAJ. Factors fetermining success and energy requirements 1991; 78: 85-95.

10 Gosselink AT, Crijns HJ, Van Gelder IC, Hillige H, Wiesfeld AC, Lie KI. Low-dose amiodarone for maintenance of sinus rhythm after cardioversion of atrial fibrillation or flutter. ¥AMA 1992; 267: 3289-93.

11 Griffith GC, Stragnell R, Levinson DC, Moore FJ, Ware AG. Study of beneficial effects of FJ, Ware AG. Study of beneficial effects of anticoagulant therapy in congestive hear

12 Atrial Fibrillation Investigators. Risk factors for stroke and efficacy of antithrombotic treatment in atrial fibrillation: analysis of pooled data from randomized controlled trials. Arch Intern Med 1994; 154: 1449-57. 